\title{
The Fly as a Model for Neurodegenerative Diseases: Is It Worth the Jump?
}

\author{
Ruben J. Cauchi Marcel van den Heuvel \\ MRC Functional Genetics Unit, Department of Physiology, Anatomy and Genetics, University of Oxford, Oxford, UK
}

\section{Key Words}

Neurodegeneration $\cdot$ Neuroprotection $\cdot$ RNA $\cdot$ Drosophila $\cdot$

Spinal muscular atrophy • Fragile X-associated tremor/ataxia syndrome - Alzheimer's disease - Parkinson's disease •

Hereditary spastic paraplegia $\cdot$ Polyglutamine diseases

\begin{abstract}
Neurodegenerative diseases are responsible for agonizing symptoms that take their toll on the fragile human life. Aberrant protein processing and accumulation are considered to be the culprits of many classical neurodegenerative diseases such as Alzheimer's disease, tauopathies, Parkinson's disease, amyotrophic lateral sclerosis, hereditary spastic paraplegia and various polyglutamine diseases. However, recently it has been shown that toxic RNA species or disruption of RNA processing and metabolism may be partly to blame as clearly illustrated in spinal muscular atrophy, spinocerebellar ataxia 8 and fragile $\mathrm{X}$-associated tremor/ataxia syndrome. At the dawn of the twenty-first century, the fruit fly or Drosophila melanogaster has taken its place at the forefront of an uphill struggle to unveil the molecular and cellular pathophysiology of both protein- and RNA-induced neurodegeneration, as well as discovery of novel drug targets. We review here the various fly models of neurodegenerative conditions, and summarise the novel insights that the fly has contributed to the field of neuroprotection and neurodegeneration.

Copyright $\odot 2006$ S. Karger AG, Basel
\end{abstract}

\section{KARGER}

Fax +4161306 1234

E-Mail karger@karger.ch

www.karger.com
(C) 2006 S. Karger AG, Basel

$1660-2854 / 06 / 0036-0338 \$ 23.50 / 0$

Accessible online at:

www.karger.com/ndd

\section{Introduction}

Human neurodegenerative diseases are responsible for devastating symptoms such as ataxia, tremor, movement disorders, and cognitive and memory loss, all because of dysfunction and loss of specialised neurons. The pathogenicity of such diseases can be triggered either at the protein level as is the case in Alzheimer's disease (AD), tauopathies, Parkinson's disease (PD), amyotrophic lateral sclerosis (ALS), hereditary spastic paraplegia and various polyglutamine (polyQ) diseases, or at the RNA level, a recently emerging neurodegenerative mechanism observed in spinal muscular atrophy (SMA), spinocerebellar ataxia (SCA) 8 and fragile-X-associated tremor/ ataxia syndrome (FXTAS). Following the identification of their hereditary component, the modelling of neurodegenerative diseases in transgenic or mutant animal models is considered a great feat of the past decade. Beyond doubt, the fruit fly or Drosophila melanogaster stands out as an excellent model organism for gene function studies thanks to the relative ease with which it is amenable to genetic manipulation and large-scale genetic screening. The evidence we put forward in this review illustrates the giant strides made using this simple organism in unveiling the molecular and cellular pathophysiology of neurodegeneration, as well as its potential in discovering novel drug targets for long-sought therapeutics. 


\section{The Strong Case for Drosophila Models of Human Disease}

The first and foremost reason why flies are exploited as models of human diseases is based on the presumption that fundamental aspects of cell biology in flies have been conserved throughout evolution in higher-order organisms such as humans. A recent report demonstrating that approximately $75 \%$ of the disease-related loci in humans have at least one Drosophila homologue cements this high degree of conservation present in flies [1]. Furthermore, studies of developmental events in the fly and subsequent similar studies in higher animals have revealed a stunning degree of functional conservation of genes, as exemplified by the hedgehog gene which encodes a cell-cell communication molecule [2]. These studies indicate that not only basic cell biology but also higher-order events such as organ 'construction' and function are conserved. Second, for flies, size does not matter at least with respect to their brains. Indeed, the fly brain is estimated to have, strikingly enough, in excess of 300,000 neurons and similarly to mammals is organised into areas with separated specialised functions such as learning, memory, olfaction and vision. Third, an unparalleled advantage of invertebrates is the ability to carry out large-scale genetic screens inexpensively and rapidly for mutations affecting a relevant process. Fourth, Drosophila has an unrivalled battery of genetic tools including a rapidly expanding collection of mutants, transposon-based methods for gene manipulation, systems that allow controlled ectopic gene expression and balancer chromosomes. The latter are special chromosomes made up of multiple inverted segments that suppress recombination together with visible and molecular markers, which allow chromosomal features (e.g. lethal mutations and deletions) to be followed indefinitely through crosses and generations. The above characteristics of such a minuscule system model, combined with the rapid generation time, inexpensive culture requirements, large progeny numbers produced in a single cross and a small highly annotated genome devoid of genetic redundancy, are poised to yield seminal insights into human disease.

\section{The Making of a Fly Model}

The classical and most reliable path to examine a disease-related gene in Drosophila is to generate a loss-offunction mutation in the fly homologue. Historically, this was done using genetic techniques to disrupt the gene, for instance using transposable viral-like elements or mutagenic chemicals (fig. 1a). However, in the age of genomics combined with large-scale efforts to map and open up the fly genome, banks of mutants and deletions are the present and future. These enable the fly workers to find their required mutant via internet-based search engines and a simple academically open ordering system. Transposable elements have, in flies, also been employed to generate transgenic animals. The DNA viral elements of these $P$ elements are used as vehicles to insert a 'new' gene into the host genome [3]. This technique is efficient and transgenic animals are produced at a high rate. The ability to generate multiple transgenic lines for each construct statistically diminishes any potential integration site effects. As in higher animals, fusion genes have been made, with a recent trend in life imaging being provided with a large number of green fluorescent protein-protein fusion transgenic animals.

If the disease protein or untranslated RNA has a dominant effect, another approach would be to overexpress the cognate gene in a wild-type fly background. Indeed, thanks to the well-established GAL4/upstream activating sequence (GAL4/UAS) bipartite expression system, transgenes can be expressed in either various tissues or in a small group of specific cells [4] (fig. 1b). This technique has also been used quite recently to knockdown an endogenous gene by expressing a transgenic RNA interference (RNAi) construct that expresses double-stranded hairpin RNAs capable of suppressing translation or degrading homologous mRNAs in specific spatial or temporal patterns.

RNAi transgene techniques are useful, but it is never clear if the effect is loss-of-function or merely a knockdown. In addition, non-specific effects are possible and these have been documented in a recent report [5]. The flippase (Flp)/flippase recombinase target (FRT) genetic mosaic system is capable of achieving the same goals without the problems associated with RNAi, and consequently this innovative technique has gained considerable showing in the engineering blueprint of fly disease models. The mechanics of this system involve yeast Flprecombinase-mediated mitotic recombination between FRT sites integrated at identical positions on homologous chromosomes [6]. This results in the generation of a clone of cells homozygous for a mutagenised chromosome arm, which can be screened for a disease-specific phenotype. By controlling the space and time of the recombination event, only the cells of interest at a specific time are made homozygous (fig. 1c). As a result, this technique allows the uncovering of tissue-specific phenotypes generated 

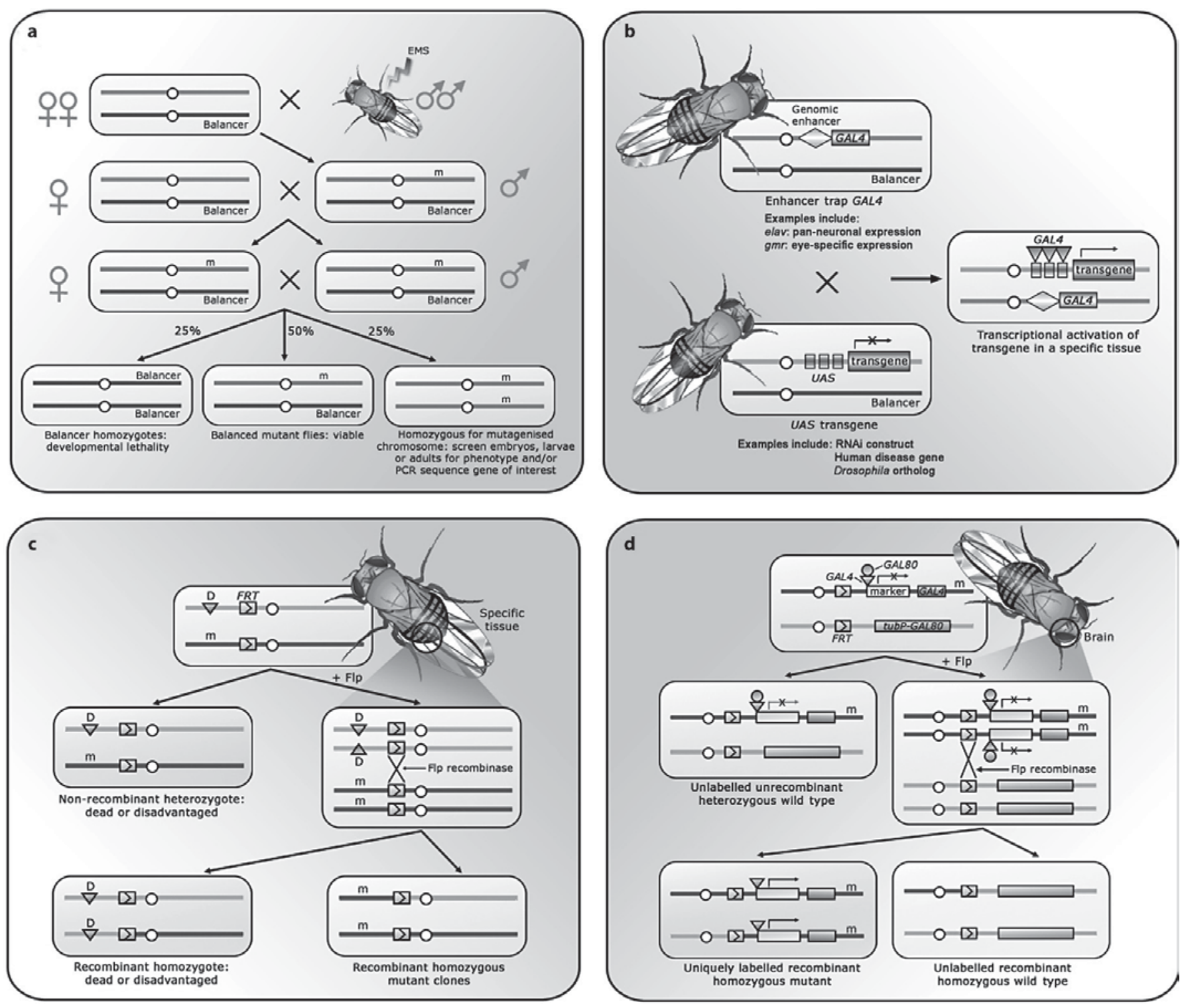

Fig. 1. Commonly used genetic approaches to studying genes causing neurodegenerative diseases in Drosophila. a A classical crossing scheme used to generate point mutations on an autosomal chromosome using the chemical mutagen ethyl methane sulphonate (EMS). b Using the GAL4/UAS system, a transgenic fly having either the disease-causing gene or an RNAi construct placed under the control of GAL4-responsive multiple $U A S$ sites is crossed to a number of well-characterised transgenic lines or 'drivers', expressing the yeast transcriptional activator GAL4 in a variety of tissue- and cell-type-specific patterns. c The powerful Flp/FRT system allows site-specific recombination between homologous chromosomes following DNA replication. In this way, the region of the chromosome arm distal to the FRT site will be

made homozygous and upon segregation, half of the daughter cells will inherit two copies of this region from one of the parental chromosomes. By introducing tissue-specific dominant lethal or disadvantageous mutations, recombinant homozygous mutant cell clones can be generated which can be screened for a phenotype. $\mathbf{d}$ On the other hand, in the mosaic analysis with a repressible cell marker modification, recombinant homozygous mutant cell populations are uniquely distinguished because they lack repression of a UAS marker gene. $t u b P-G A L 80=G A L 80$ driven by the tubulin $1 \alpha$ promoter; $\mathrm{m}=$ mutation; $\mathrm{D}=$ dominant lethal $\left(\right.$ ovo $\left.^{D 1}\right)$ or disadvantageous (Minute) mutation; $g m r=$ glass multimer reporter. 
a

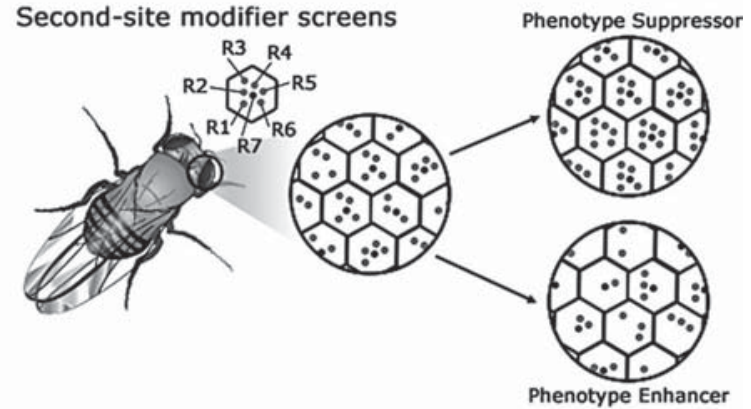

b Phenotypic characterisation of model

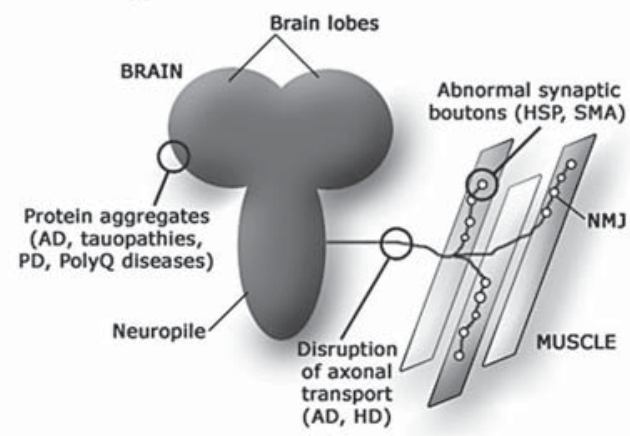

c Pharmacological rescue

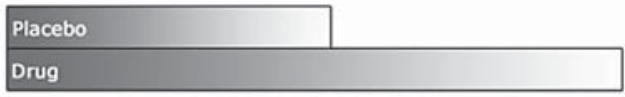

Improvement of pathological features

Fig. 2. Getting the most out of fly models of neurodegenerative disease. Second-site modifier screens, phenotypic characterisation and pharmacological rescue constitute the three most powerful exploits of fly neurodegenerative disease models. a In the context of neurodegenerative diseases, second-site modifier screens are commonly carried out in the fly's compound eye, which contains a multitude of unit eyes or ommatidia. Each ommatidium contains 8 photoreceptor cells (R1-R8), of which 7 are usually visible in a single microscopic plane. $\mathbf{b}$ The nervous system of vertebrates and invertebrates is very similar. A schematic of the larval brain is shown here. Motor neurons project from the neuropile (equivalent to the vertebral column in vertebrates) towards muscles where they form neuromuscular junctions (NMJs). Because the fly nervous system is well characterised and highly accessible, its phenotypic analysis is undemanding. HD = Huntington disease; HSP = hereditary spastic paraplegia. c Discovery of drug compounds that positively modulate the disease phenotypes in fly neurodegenerative models is considered the holy grail in the field of neurodegenerative therapeutics. by mutations in essential genes regardless of their other functions in development. An ingenious improvement on this system was the addition of markers or genetic tricks. Indeed, if it is desirable to create large (or domineering) mutant areas, the chromosome arm carrying the normal allele can be modified with a dominant lethal mutation, for example $o v o^{D 1}$, a dominant female sterile mutation that leads to degeneration of the germline when present, and is used to generate a homozygous mutant female germline [7-9], or dominant disadvantageous mutations, such as the metabolic mutation Minute. Furthermore, the 'mosaic analysis with a repressible cell marker' technique is commonly used to establish uniquely labelled neuronal populations homozygous for a mutation of interest within an otherwise phenotypically wild-type nervous system [10]. In mosaic analysis with a repressible cell marker, heterozygous flies ubiquitously express GAL80, which in turn suppresses GAL4-dependent expression of a UASlinked marker gene. Upon recombination and segregation, daughter cells homozygous for the mutant gene are established. Since these clones no longer express GAL80, the marker gene can be specifically turned on by GAL4 to uniquely label homozygous mutant cells (fig. 1d).

Once a fly model is established, the resulting phenotype can be thoroughly investigated to provide cellular and molecular insights into the pathogenesis of the disease in question (fig. 2). Given the powerful genetics of the fly, an obvious step would be the uncovering of second-site modifiers, opening the door further to molecular characterisation and possibly therapeutic manipulation. Such screens have often been carried out using the adult compound eye because of its tolerance to genetic disruption of basic biological processes, its dispensability for survival of the fly under laboratory conditions and the ease with which disruption of photoreceptors can be detected. However, it is important to note that the cellular environment of the fly's retina may differ from that of the neuronal tissue specifically affected by the condition under investigation and, because of this caveat, some of the identified interactions may prove false [11]. Flies also provide a platform for rapid drug discovery because it is easy to generate large numbers of genetically identical animals that can be tested in drug screens. Such work is prone to contribute to the identification of novel hits in the lengthy pharmaceutical pipeline. Last but not least, it is important to note that any model is not an exact phenocopy of the respective human condition and this therefore always hinders a complete understanding of a disease progress and/or assessment of therapies. This limitation putatively weighs heavily on Drosophila considering its large evolutionary distance from humans. 
Table 1. Fly models of neurodegenerative diseases

\begin{tabular}{|c|c|c|}
\hline Disease & Generation of model & Reference \\
\hline \multicolumn{3}{|c|}{ Protein-mediated neurodegeneration } \\
\hline \multirow[t]{3}{*}{$\mathrm{AD}$} & Expression of human $\mathrm{A} \beta 40, \mathrm{~A} \beta 42, \mathrm{APP}, \beta$-secretase, and presenilin transgenes & $22-24$ \\
\hline & Loss-of-function mutations in $d P S$ & $18-20$ \\
\hline & $\begin{array}{l}\text { Expression of } d P S \text { bearing familial AD-associated mutations in a } d P S \text { null } \\
\text { background }\end{array}$ & 21 \\
\hline Tauopathies & Expression of wild-type and mutant human tau transgenes & $25-28$ \\
\hline \multirow[t]{6}{*}{$\mathrm{PD}$} & Exposure to rotenone & 31 \\
\hline & Expression of human wild-type and mutant (A30P, A53T) $\alpha$-synuclein & 32 \\
\hline & Disruption of $d$ Parkin & $38-40$ \\
\hline & Expression of the hParkin substrate protein, Pael-R & 41 \\
\hline & Disruption of $D J-1$ Drosophila homologues: $D J-1 a$ and $D J-1 b$ & $43-46$ \\
\hline & Disruption of $d P i n k 1$ & $48-51$ \\
\hline PolyQ diseases & Expression of polyQ chains alone & 52,53 \\
\hline $\mathrm{HD}$ & $\begin{array}{l}\text { Expression of a polyQ-expanded (Q75, Q93, Q120, Q128) amino-terminal } \\
\text { fragment of human Htt }\end{array}$ & $58,60,61$ \\
\hline SCA3 & $\begin{array}{l}\text { Expression of wild-type (Q27) and mutant (Q78) versions of a carboxy- } \\
\text { terminal fragment of the human Atx3 gene }\end{array}$ & 66 \\
\hline SCA2 & Disruption of $d A t x 2$ & 68 \\
\hline \multirow[t]{2}{*}{ SCA1 } & $\begin{array}{l}\text { Expression of full-length wild-type (Q30) and mutant (Q82) versions of the } \\
\text { human Atx1 gene }\end{array}$ & 69 \\
\hline & Overexpression of $d A t x 1$ & 72 \\
\hline SBMA & Expression of full-length mutant $h A R(\mathrm{Q} 52)$ & 74 \\
\hline \multirow[t]{2}{*}{ ALS } & Disruption of $d S O D$, the fly homolog of human SOD1 & 76,77 \\
\hline & Expression of human SOD1 mutant transgenes in a $d S O D$ null background & 76 \\
\hline \multirow[t]{3}{*}{ HSP } & Loss-of-function mutations in dSpastin & 81 \\
\hline & RNAi knockdown of dSpastin & 82,117 \\
\hline & $\begin{array}{l}\text { Expression of } d \text { Spastin bearing a conserved pathogenic mutation (K467R } \\
\text { substitution corresponding to the K388R mutation in human Spastin gene) } \\
\text { in a wild-type background }\end{array}$ & 82 \\
\hline Excitotoxicity & RNAi knockdown of $d E A T T 1$ & 84 \\
\hline \multicolumn{3}{|c|}{ RNA-mediated neurodegenerative diseases } \\
\hline FXTAS & Expression of the human FMR1 with premutation (90 CGG repeats) & 101 \\
\hline SCA8 & $\begin{array}{l}\text { Expression of wild-type (CTG9) and repeat-expanded (CTG112) human SCA8 } \\
\text { non-coding RNA }\end{array}$ & 102 \\
\hline \multirow[t]{2}{*}{ SMA } & Disruption of $d S M N$ by ectopic expression of human SMN & 106 \\
\hline & Loss-of-function mutations in $d S M N$ & 107 \\
\hline
\end{tabular}

SBMA = Spinobulbar muscular atrophy; hAR = human androgen receptor; HSP = hereditary spastic paraplegia; for other abbreviations, see text.

\section{Modelling Protein-Induced Neurodegeneration in the Fly}

Many neurodegenerative diseases are the result of pathogenicity initiated at the protein level, most commonly the result of aberrant protein processing and accumulation. AD, tauopathies, PD, ALS, hereditary spastic paraplegia, various polyQ diseases and the emerging excitotoxicity-induced neurodegeneration, all constitute clear examples of this pathogenic platform (table 1).

\section{Alzheimer's Disease}

$\mathrm{AD}$ is clinically characterised by progressive memory loss accompanied by pathological features including extracellular senile plaques containing $\beta$-amyloid $(A \beta)$ peptides, formation of neurofibrillary tangles and progressive neuronal loss. Secretion of A $\beta$ peptides is the result of sequential cleavage of $A \beta$ precursor protein (APP) by $\beta$-secretase, a type I transmembrane glycosylated aspartyl protease, and $\gamma$-secretase, a large protein complex composed of at least 4 proteins, presenilin (PS) 
1 or 2, nicastrin, Aph-1 and Pen-2. In the absence of pathology, the heterogenous cleavage nature of $\gamma$-secretase gives rise to a series of $A \beta$ peptides, including the major species $A \beta 40$ and a smaller amount of $A \beta 42$. Genetic analyses of familial AD identified mutations in the APP, PS1 and PS2 genes, all of which are associated with altered APP processing and lead to an increased generation of $A \beta 42$ peptide, the primary neurotoxic species involved in $\mathrm{AD}$ pathogenesis (for review, see Nussbaum and Ellis [12]).

Due to the lack of conservation of the $A \beta$ domain in the Drosophila APP-like protein (APPL) [13] and the absence of $\beta$-secretase activity [14], modelling AD in the fly proved to be a challenging experience. Many focused on unravelling the physiological functions of APP and APPL in Drosophila. Both proteins were shown to function as vesicular receptors for kinesin 1, a motor mediating anterograde vesicle trafficking. Indeed flies lacking APPL or overexpressing human APP and Drosophila APPL constructs have axonal transport defects, which are enhanced by reductions in kinesin 1 expression. Furthermore, overexpression of the A $\beta$-domain-containing APP but not APPL induced neuronal apoptosis $[15,16]$. APPL has also been implicated in promoting synaptic formation at the neuromuscular junction (NMJ) [17]. Turning their attention to the Drosophila PS (dPS) gene, several research groups revealed that dPS is required for the production of notch proteolytic products implicated in signalling. Consequently, loss-of-function mutations in the $d P S$ gene abolish notch signal transduction and enhance apoptosis in developing tissues [18-20]. Attempting to dissect the clinical heterogeneous nature of familial AD associated with PS gene mutations, Seidner et al. [21] introduced familial AD-linked mutations at conserved residues in $d P S$ transgenes expressed in flies lacking endogenous $d P S$ activity. The mutant phenotypic spectrum observed in flies correlated with that observed in human patients, thus suggesting that clinical heterogeneity depends on human PS mutant lesions rather than genetic or environmental factors.

Modelling AD in the fly was also attempted by delivering transgenes encoding the human $A \beta 40$ and $A \beta 42$ peptides. When specifically expressed in the brain, both $A \beta 40$ and $A \beta 42$ led to age-dependent learning defects, but only $A \beta 42$ was capable of causing the formation of diffuse amyloid deposits in Kenyon cells (principal neurons of the fly's mushroom bodies, which are highly plastic brain regions essential for many forms of learning and memory), locomotor dysfunction and extensive neurodegeneration, all of which are exacerbated with age. Fur-

The Fly as a Model for Neurodegenerative Diseases thermore, the life-span of $A \beta 42$ transgenic flies was also much shorter, whereas that of $A \beta 40$ transgenic flies was not affected [22]. When expression was directed in the eye, $A \beta 42$ but not $A \beta 40$ flies exhibited progressive eye disorganisation, the severity of which depended on the expressed amounts of the peptide. The authors also screened for genetic modifiers of the A $\beta 42$-induced rough-eye phenotype. Their efforts paid off because overexpression of the Drosophila neprilysin gene was found to suppress the $A \beta 42$ phenotypes by lowering the levels of the $A \beta 42$ peptide [23]. This result opened up the possibility of neprilysin up-regulation as a novel preventive and therapeutic approach to AD.

Using a different approach, Greeve et al. [24] showed that expression of human APP in the eye alone, or in combination with human $\beta$-secretase, resulted in progressive degeneration of retinal photoreceptors and agedependent $A \beta$ plaque formation. Both phenotypes were completely absent when $\beta$-secretase was expressed alone. Moreover, when APP, $\beta$-secretase and an additional copy of the $d P S$ gene were expressed ubiquitously, flies demonstrated semi-lethality and ectopic wing vein formation, both of which were absent when $d P S$ was expressed alone or in combination with $\beta$-secretase. The observed phenotypes were suppressed by the introduction of $d P S$ loss-offunction mutations and by secretase inhibitors, a clear demonstration that this fly model reconstitutes some of the human phenotypes and molecular findings in $\mathrm{AD}$. Undeniably this fly model can now be employed to screen for genes, drugs or metabolites that modulate APP processing and have the potential to decrease $A \beta$-induced cellular degeneration.

\section{Tauopathies}

Neurofibrillary tangles which are composed of abnormally phosphorylated forms of the microtubule-binding protein, tau, constitute the pathological hallmarks of tauopathies, a group of neurodegenerative diseases that include $\mathrm{AD}$ and the frontotemporal dementias. To model tauopathies, Wittmann et al. [25] expressed wild-type and mutant forms of human tau in the fly in a pan-neuronal pattern. Similar to the situation observed in afflicted humans, transgenic flies have adult-onset, progressive brain neurodegeneration, a shortened life-span, enhanced toxicity of mutant tau, and accumulation of abnormal tau with the exception that neurofibrillary tangles containing tau protein do not form. Hyperphosphorylation of tau by shaggy, the Drosophila glycogen synthase kinase $3 \beta$ homologue and wingless pathway component, not only exacerbates the neurodegeneration caused by 
tau but also stimulates a neurofibrillary-tangle-like pathology in Drosophila. Furthermore, the authors established that the effect of glycogen synthase kinase $3 \beta /$ shaggy is likely independent of its classical Wnt role though 2 downstream components of the Wnt signalling pathway, $\beta$-catenin and T-cell factor, were found to have a distinct role in modulating tau-induced neurodegeneration [26]. In line with this, inhibitors of glycogen synthase kinase $3 \beta$ were found to ameliorate the development of the tau fly phenotype, thereby establishing a novel therapeutic strategy for tauopathies [27].

Overexpression of human tau in Drosophila larval motor neurons disrupts axonal transport and causes impaired locomotion [27]. On trying to dissect the mechanism of tau-mediated neuronal dysfunction, Chee et al. [28] found that NMJs exhibit defective synaptic transmission, which may be the result of a reduced number of functional mitochondria in the presynaptic terminal. Recently, Shulman and Feany [29] were successful in conducting a screen for genetic modifiers of a tau-induced rough-eye phenotype. Whilst kinases and phosphatases comprised the major class of modifiers uncovered thus underlining the significance of phosphorylation on tau toxicity, other modifiers included apoptotic regulators, cytoskeleton components and the Drosophila homologues of the proteins implicated in fragile-X mental retardation (FMR) and SCA2. Continuing the search for tau modifiers, Karsten et al. [30] have recently identified puromycin-sensitive aminopeptidase as an inhibitor of tau-induced neurodegeneration by performing gene expression analyses in multiple brain regions of mice expressing mutant human tau followed by validation in the Drosophila tau model. These results have important implications for the development of therapies in tauopathies.

\section{Parkinson's Disease}

Patients afflicted with PD experience resting tremor, postural instability, bradykinesia and rigidity. The characteristic pathological hallmarks of this common movement disorder include loss of dopaminergic neurons in the substantia nigra, formation of Lewy bodies, which are ubiquitinated protein accumulations in neuronal perikarya, and Lewy neurites, which are similar protein aggregates found in neuronal processes. Although a number of genes causative of the rare familial forms of $\mathrm{PD}$ have been discovered, most cases of PD are sporadic and thought to be caused by both exogenous environmental toxins and endogenous proteotoxins (for a review, see Nussbaum and Ellis [12]).
In an attempt to model sporadic PD in Drosophila, Coulom and Birman [31] reported that flies treated with rotenone, which is a mitochondrial complex I inhibitor and a widely used pesticide, recapitulated the main symptomatic features of PD including locomotor impairments and loss of dopaminergic neurons in all of the brain clusters. The antioxidant melatonin alleviated both these phenotypes, suggesting that this agent may be beneficial in the treatment of PD.

The discovery of familial PD-associated genes offered the opportunity to study mechanisms of both familial and sporadic mechanisms of PD pathogenesis in model organisms. One of the familial PD-linked genes that have been intensively studied in Drosophila encodes $\alpha$-synuclein, a soluble, natively unfolded presynaptic neuronal protein and a major constituent of both Lewy bodies and Lewy neurites. Feany and Bender [32] were the first to show that expression of normal and mutant forms of human $\alpha$-synuclein in the fly leads to adult-onset loss of tyrosine-hydroxylase-positive dopaminergic neurons. This was associated with filamentous $\alpha$-synuclein-rich intraneuronal inclusions and locomotor dysfunction, thereby recapitulating the essential features of the human disorder. Using this fly model, the same group showed that increased Ser129 phosphorylation in human $\alpha$-synuclein correlated with enhanced neurotoxicity. On the other hand, blocking phosphorylation not only had the opposite effect but also increased formation of inclusion bodies, hence implicating that the latter may protect neurons from $\alpha$-synuclein toxicity [33].

In an effort to find modifiers of human $\alpha$-synuclein toxicity in Drosophila, Auluck et al. [34] reported that direct expression of the human molecular chaperone heat shock protein (Hsp) 70 prevented dopaminergic neuronal loss despite the continued presence of aggregate pathology, whereas interference with endogenous chaperone activity accelerated this phenotype. In addition, $\alpha$ synuclein transgenic flies treated with geldanamycin were completely protected against $\alpha$-synuclein neurotoxicity [35]. Geldanamycin is a drug that interferes with the activity of the molecular chaperone Hsp90, which in turn functions as a negative regulator of the heat shock transcription factor that mediates Hsp70 and Hsp40 expression. These observations suggest that chaperones play a significant role in $\alpha$-synuclein pathologies and modulation of molecular chaperone activity may be an effective approach in the treatment of PD. A recent study aimed at identifying $\alpha$-synuclein cytotoxicity modifiers adopted a cross-species strategy. By conducting a genome-wide overexpression screen in a yeast PD model, Cooper et al. 
[36] found that the large class of toxicity modifiers were proteins functioning in endoplasmic reticulum-to-Golgi vesicular trafficking. Elevated expression of a mammalian homologue of one such modifier, the Rab guanosine triphosphatase, Yptlp, protected against $\alpha$-synuclein-induced dopaminergic neuron loss in various animal models of PD including Drosophila.

Reaping the fruits of high-density oligonucleotide microarrays, Scherzer et al. [37] attempted temporal profiling of progressive gene expression changes in human $\alpha$ synuclein transgenic flies, with the goal of revealing the molecular machinery mediating neurotoxicity in vivo and identifying potential targets for neuroprotective drugs. Various transcripts including those encoded by lipid processing, energy, membrane transport and defence response genes were tightly associated with $\alpha$-synuclein expression, thus indicating that perturbed vesicle membrane fusion and permeability together with early mitochondrial damage may underlie neurotoxicity in transgenic flies. Additionally, there was no significant overlap between the transcriptional programmes observed in the fly models of PD and tauopathy, suggesting highly distinct pathways of neurodegeneration in both diseases.

Autosomal recessive juvenile-onset parkinsonism has been linked to 3 genes, Parkin, DJ-1 and PTEN-induced putative kinase 1 (Pink1), which are somehow involved in mitochondrial function. Parkin is an E3-specific ubiquitin ligase and its conservation in Drosophila (dParkin) made it amenable to direct genetic investigation. Indeed, dParkin null flies exhibited a reduced life-span, locomotor defects, infertility, a reduction in cell size and number, and a progressive degeneration of a subset of dopaminergic neurons [38-40]. Profound mitochondrial defects were the earliest detectable phenotypes associated with muscle degeneration and defective spermatids in dParkin mutants, raising the question of whether dParkin is required for mitochondrial integrity $[38,39]$. Progressive degeneration of dopaminergic neurons was also observed when the human Pael receptor (Pael-R), a parkin ubiquitination target, was expressed pan-neuronally. Co-expression of human parkin (hParkin) rescued Drosophila neurotoxicity by degrading Pael-R, whilst in vivo knockdown of dParkin promoted Pael-R accumulation and accelerated Pael-R-induced neurodegeneration. Moreover, co-expression of $\alpha$-synuclein and hParkin was associated with both reduced $\alpha$-synuclein-induced neurodegeneration and reduced inclusion formation [41]. All this evidence seems to suggest parkin is an important neuronal protective factor that is molecularly associated with the $\alpha$-synuclein-associated phenotypes.

The Fly as a Model for Neurodegenerative Diseases
Substantial evidence suggests that parkin may also confer protection from the effects of oxidative stress. Indeed recent results from transcriptional profiling of dParkin fly mutants and a genetic screen for dParkin modifiers demonstrated that oxidative stress response elements are up-regulated and loss-of-function mutations in oxidative stress response components enhanced the dParkin mutant phenotypes [42]. Further work by the same group on glutathione S-transferase S1, a factor that has been implicated in the cellular response to oxidative stress and one of the modifier genes uncovered in the above screen, revealed that its overexpression rescued the degeneration of dopaminergic neurons in dParkin fly mutants [40]. Inducing glutathione $\mathrm{S}$-transferase expression in mammals may therefore be a promising therapeutic strategy for PD.

Drosophila possesses 2 homologues of human DJ-1: a ubiquitously expressed $D J-1 \beta$ and $D J-1 \alpha$, which is predominantly expressed in the male germline. Attempting to dissect the function of these 2 genes, Meulener et al. [43] showed that $D J-1 \alpha$ and $D J-1 \beta$ double null flies are viable, fertile, have a normal life-span and do not suffer a progressive loss of dopaminergic neurons. However, they are associated with a selective sensitivity to agents that induce oxidative stress, including the environmental toxins rotenone and paraquat. A separate study revealed that single $D J-1 \beta$ null flies exhibited an extended survival of dopaminergic neurons and a differential response to different forms of oxidative stress. Indeed, a compensatory up-regulation of $D J-1 \alpha$ protected $D J-1 \beta$ mutant flies against paraquat insult, but not against hydrogen peroxide [44]. Recently, Park et al. [45] have reported that $D J-1 \beta$ mutants also have oxidative-stress-sensitive locomotive dysfunction. Whilst these studies failed to show a defect in dopaminergic neurons thereby undermining the suitability of Drosophila to model autosomal recessive juvenile-onset parkinsonism as a result of $D J-1$ dysfunction, an alternative approach undertaken by Yang et al. [46] seemed to have alleviated this problem. Specifically, the authors inactivated $D J-1 \alpha$ by transgenic RNAi to reveal that $D J-1 \alpha$ knockdown flies show cellular accumulation of reactive oxygen species, hypersensitivity to oxidative stress, and degeneration of dopaminergic and photoreceptor neurons. Furthermore, components of the phosphatidylinositol-3-kinase/Akt-signalling pathway were identified as specific modifiers of $D J-1 \alpha$ RNAi-induced neurodegeneration, possibly establishing another avenue for the treatment of PD.

Following the discovery of the mitochondrial kinase, Pinkl, as a novel gene linked to autosomal recessive juvenile-onset parkinsonism, 2 years ago [47], evidence from

Neurodegenerative Dis 2006;3:338-356 
Drosophila lately added a twist to an emerging pathophysiology of PD. Indeed, several recent studies demonstrate that knockdown [48] or loss-of-function $[49,50]$ mutants in the Drosophila Pink1 homologue (dPink1) have mitochondrial dysfunction that is phenotypically translated into locomotive defects, defective sperm production, shortened life-span and degeneration of indirect flight muscles and dopaminergic neurons. Transgenic expression of dParkin (but not $d D J-1$ ) suppressed the $d P i n k 1$ loss-of-function phenotypes but not vice versa, implicating that although both proteins function in a common pathway that regulates mitochondrial physiology, dParkin functions downstream of $d$ Pinkl. Intriguingly, Wang et al. [51] show that treatment with antioxidants or expression of the human $\mathrm{Cu}-\mathrm{Zn}$ superoxide dismutase 1 (SOD1) suppressed the neurodegeneration induced by $d P i n k 1$ inactivation, thereby showing that dPink1 may play a neuroprotective role against undergoing neuronal oxidative stress. We anticipate that additional Drosophila work on dPink1-dParkin will help to further clarify the neurodegenerative saga of PD.

\section{Polyglutamine Diseases}

A group of human neurodegenerative diseases known collectively polyQ diseases are caused by an expansion of a CAG repeat within the open reading frame (or proteincoding region) of the disease gene. The expanded repeat is translated into an expanded tract of glutamines that confers a dominant toxicity to the respective disease protein, leading to dysfunction and late-onset neurodegeneration in selective neurons. To date 9 polyQ diseases have been identified, including Huntington's disease (HD), spinobulbar muscular atrophy, dentatorubralpallidoluysian atrophy and 6 SCAs (1, 2, 3, 6, 7 and 17).

Expanded polyQ chains alone are intrinsically cytotoxic, produce aggregates and lead to neuronal degeneration and early adult death when expressed in Drosophila neurons [52]. Using transgenic flies expressing polyQ chains alone, Kazemi-Esfarjani and Benzer $[53,54]$ uncovered Drosophila homologues of human Hsp40/HDJ1, human tetratricopeptide repeat protein 2 and human myeloid leukaemia factor 1 as suppressors in a screen for genetic factors modifying polyQ-mediated eye neurodegeneration. Expression of the expanded polyQ-containing peptides in Drosophila neurons attenuated cAMP-response-elementbinding-protein (CREB)-responsive transcription. In line with this, a mutation in the CREB fly homologue, dCREB2, enhanced polyQ-induced lethality, suggesting that part of the polyQ-induced phenotypes can be attributed to transcriptional deregulation [55].
Attention also focused on gaining insights into the pathophysiology of polyQ in the context of known disease proteins. Many authors decided to use truncated instead of full-length versions of their protein of interest. In the case of HD this may be the result of technical difficulties imposed by the massive size of the causative protein combined with the additional strain of an engineered polyQ domain. It is crucial to note that the use of truncated proteins may render the results obtained from these models incomplete especially in view of recent studies underscoring the importance of the protein framework in the modulation of polyQ-induced neurodegeneration $[56,57]$.

$\mathrm{HD}$ is an autosomal dominant disease caused by the expansion of a polyQ repeat in the huntingtin $(\mathrm{Htt})$ protein. Characterised by a combination of chorea, cognitive impairment and affective changes, HD is one of the polyQ diseases that was successfully modelled in the fly. Indeed, both reduced expression of the Drosophila Htt orthologue $(\mathrm{dHtt})$ and expression of the polyQ repeat-expanded amino-terminal fragment of human Htt resulted in neuronal organelle accumulations characteristic of disrupted axonal transport, progressive neurodegeneration [58] and reduced viability [59]. Furthermore, similar to the human situation, the age of onset and severity of neuronal degeneration correlated with the repeat length [60]. In another Drosophila model with a pan-neuronal expression of a larger amino-terminal fragment of the human $\mathrm{Htt}$ gene having a pathogenic polyQ tract, Lee et al. [61] observed a progressive loss of motor coordination, decreased viability and progressive formation of $\mathrm{Htt}$ aggregates specifically in the cytoplasm and neurites. The authors also reported that $\mathrm{Htt}$ aggregates were able to sequester other expanded polyQ proteins in the cytoplasm and to physically obstruct axonal transport. Conversely, flies expressing an expanded polyQ tract either alone or in the context of the SCA3 protein did not present with axonal trafficking disruption, thus suggesting that axonal transport defects may not be a universal phenomenon in polyQ disorders.

The HD fly models served as the bedrock for studying the effect of a myriad of modifiers on HD pathology. Indeed, following the in vitro demonstration that the mutant polyQ-containing domain of human Htt, Htt exon 1 protein (Httexlp), interacts directly with the acetyltransferase domains of histone acetyltransferases to inhibit their acetyltransferase activity, Steffan et al. [59] reported that both genetic and pharmacological reductions in the activity of histone deacetylases were found to reduce the rate and extent of polyQ-induced pathology in transgenic Drosophila expressing expanded repeat Httexlp as well as 
expanded polyQ peptide alone. In another study, a synthetic bivalent Htt-binding peptide suppressed polyQ aggregation and pathogenesis in transgenic Drosophila expressing expanded polyQ polypeptides, thereby suggesting that in addition to inhibiting histone deacetylases, targeting protein interactions leading to aggregate formation may also be beneficial for the design and development of therapeutic agents for HD and related diseases [62]. Furthermore, acting on in vitro evidence showing that Httexlp can be modified either by small ubiquitinlike modifier (SUMO) 1 or by ubiquitin on identical lysine residues, the same group found that abolishing Httexlp lysine residues or lowering SUMOylation activity suppressed neurodegeneration whereas reducing ubiquitination activity modestly worsened the pathology in $\mathrm{HD}$ transgenic flies [63]. These findings raise the possibility that therapeutic strategies aimed at reducing the level of SUMOylated Htt have the potential to suppress HD pathogenesis. Recently, studies from Rubinsztein's laboratory demonstrated that rapamycin, an autophagy inducer, protected against neurodegeneration not only in HD flies [64], but also in Drosophila expressing wild-type or mutant forms of tau [65], suggesting the potential of inducing autophagy to treat a wider range of aggregate diseases.

SCAs are characterised by cerebellar Purkinje cell degeneration that causes ataxia, or loss of balance and coordination. Numerous insights were also gained from fly models of SCAs. Indeed, the modelling of SCA3 or Machado-Joseph disease in Drosophila by Warrick et al. [66] about a decade ago started the ball rolling. The authors observed that targeted expression of a polyQ-expanded segment of human Ataxin-3 (Atx3), the causative gene in SCA3/Machado-Joseph disease, led to nuclear inclusion formation and late-onset neural degeneration. In later studies, the same group demonstrated that directed expression of both the human forms of Hsp70 and normal human Atx 3 suppressed neurodegeneration in the SCA3 fly model $[56,67]$. These results highlight the crucial impact of host protein function in SCA3 disease pathogenesis and once again, the therapeutic benefit of molecular chaperones in aggregate disorders. In an attempt to shed light on the role of the SCA2 gene product, Atx2, Satterfield et al. [68] investigated the Drosophila homologue dAtx2. The variety of fly phenotypes observed upon either a reduction or an increase in $d A t x 2$ activity appeared to be the result of defective actin filament formation, thus indicating that Atx 2 may have a role in regulating the cytoskeleton and possibly transport.

In an attempt to model SCA1 in the fly, FernandezFunez et al. [69] observed that expression of the full- length human SCA1 gene (Atx1) resulted in neurodegenerative phenotypes which were stronger with expanded Atxl compared to the wild type. Additionally, the authors reported the discovery of various modifiers of SCA1-induced neurodegeneration, including those involved in protein folding and clearance, RNA processing, transcriptional regulation and cellular detoxification. The 14-3-3 protein, a multifunctional regulatory molecule, was found to modify neurotoxicity by binding to and stabilizing Atx 1, thereby slowing its normal degradation. The association of Atx1 with 14-3-3 is regulated by Akt-dependent phosphorylation of serine 776 and is stronger in polyQ-expanded Atx1 compared to the wild type. As expected, overexpression of both 14-3-3 and Akt kinase intensified Atx1-induced neurodegeneration in the SCA1 fly model [70]. In line with this, overexpression of a degradatory co-chaperone of Hsp70 that facilitates the polyubiquitination of chaperone substrates ( $\mathrm{C}$ terminus of Hsp70 interacting protein) was found to decrease the protein steady-state levels of both expanded and unexpanded Atx1 and suppressed their toxicity in SCA1 flies [57]. Two recent studies implicated that Atx1 may play a role in the regulation of gene expression. Tsai et al. [71] reported that mutant Atx1-mediated aggregates in SCA1 flies sequestered the endogenous transcriptional co-repressor, silencing mediator for retinoid and thyroid hormone receptor-related ecdysone receptor-interacting factor, and consistently, a mutation in that gene enhanced the SCA1-mediated eye neurodegeneration. In another report, overexpression of the Drosophila homologue of Atx1 (dAtx1) inhibited sensory-organ development by decreasing the senseless transcription factor. Since a similar effect was observed in the Purkinje cells of human Atxl transgenic mice, the authors concluded that the Atx $1 /$ senseless interaction could contribute to the characteristic Purkinje cell degeneration in SCA1 [72]. All the above studies point to several pathways involved in SCA1 pathogenesis and their modulation holds therapeutic value. Interestingly, a recent landmark paper that established an interaction network for proteins involved in inherited ataxias using a stringent yeast 2-hybrid screen confirmed many modifiers uncovered previously in Drosophila disease models [73].

The success story of polyQ disease models in Drosophila cannot be complete without that of spinobulbar muscular atrophy or Kennedy's disease, an X-linked, adultonset neurodegenerative disorder caused by expanded polyQ stretches in the $\mathrm{N}$ terminus of the human androgen receptor gene. Attempting to model this disease in flies, Takeyama et al. [74] observed that mutant human 
androgen receptor expression in the Drosophila eye caused marked neurodegeneration with nuclear localization and structural alteration of the human androgen receptor mutant protein, only upon dietary ingestion of androgen or its known antagonists. These results suggest that the onset of spinobulbar muscular atrophy requires nuclear localisation, interestingly, together with liganddependent structural alteration of human androgen receptor mutants.

\section{Amyotrophic Lateral Sclerosis}

ALS is a progressive, nearly always fatal disorder that is characterised by dysfunction and loss of large motor neurons in the cerebral cortex and spinal cord leading to progressive muscle weakness, atrophy and eventually paralysis. Approximately $10 \%$ of ALS cases are hereditary, and a small minority of these have mutations in the gene encoding SOD1, a ubiquitously expressed enzyme that is protective against toxic superoxide radicals (for a review, see Rowland and Shneider [75]). Disruption of the Drosophila SOD1 homologue, $d S O D$, leads to reduced lifespan, increased oxidative stress, infertility, impaired locomotor activity, decreased resistance to hyperoxic stress [76] and neuropathology [77]. Furthermore, Mockett et al. [76] have recently shown that expression of human SOD1 mutant transgenes in Drosophila with a SSOD null background was associated with increased oxidative stress and decreased motor performance of abrupt onset followed by premature death. The authors also reported that the above-mentioned phenotypic manifestations were fully rescued by a single human wild-type SOD1 transgene expressing only minimal levels $(5-10 \%)$ of SOD activity. In another study, when normal human SOD1 overexpression was targeted selectively to motor neurons of flies with a normal $d S O D^{+/+}$background, a dramatic extension of life-span was observed, undeniably demonstrating that SOD is an important player in protecting motor neurons against oxidative stress [78].

\section{Hereditary Spastic Paraplegia}

Hereditary spastic paraplegias are a large group of genetically heterogenous disorders that are characterised by degeneration of motor neurons in the corticospinal tract and dorsal columns, resulting in gait disturbance due to lower-extremity spasticity and weakness [79]. Following the recent discovery that mutations in the human SPG4 locus, which encodes spastin, are responsible for approximately $40 \%$ of all dominantly inherited cases [80], various groups focused on uncovering the functions of spastin in Drosophila. Recessive loss-of-function mu- tations in the highly conserved Spastin homologue, dSpastin, give rise to defective larval NMJs including smaller, more numerous synaptic boutons, accumulation of stabilised microtubules and reduced neurotransmitter release. Indeed these defects seem to be responsible for the severe movement defects and short life-span observed in dSpastin null adult flies [81, 82]. Furthermore, neuronal knockdown of dSpastin and neuronal expression of dSpastin containing a conserved pathogenic mutation led to similar phenotypic abnormalities and in the case of the former also resulted in adult-onset neurodegeneration [82]. Administration of the microtubule-destabilising drug vinblastine ameliorated not only the locomotor and life-span defects, but also the NMJ phenotypes observed on loss of dSpastin, the latter suggesting that spastin may be a negative regulator of the microtubule cytoskeleton stability [82]. These observations in Drosophila opened the door to a pharmacological strategy aimed at modulating microtubule stability in order to effectively counter the pathological phenotypes arising in hereditary spastic paraplegias.

\section{Excitotoxicity-Induced Neurodegeneration}

Excessive or prolonged stimulation of glutamate receptors in the mammalian central nervous system (CNS) is thought to lead to neuronal hyperactivation and damage, a phenomenon observed in an ensemble of neurodegenerative disorders including acute CNS insults, HD, ALS, AD and PD (for a review, see Salinska et al. [83]). The synaptic activity of glutamate, the chief excitatory neurotransmitter in the mammalian CNS, normally terminates on its reuptake by excitatory amino acid transporters (EAATs). On knockdown of the Drosophila glutamate transporter, $d E A A T 1$, Rival et al. [84] observed hyperexcitability, reduced life-span and marked brain degeneration. The hyperexcitability phenotype was significantly rescued by exposure to riluzole, an anti-excitotoxic agent used clinically for ALS patients, and by the anti-oxidant melatonin, the latter confirming an important role of oxidative stress in excitotoxicity-induced neurodegeneration. The same group also stumbled upon evidence of a reduced glutamate buffering capacity when attempting to investigate the involvement of glial cell dysfunction in polyQ-mediated neurodegenerative diseases. Indeed, upon targeted expression of the polyQ-containing domain of Htt or an extended polyQ peptide alone in a subset of Drosophila glial cells, the authors observed a progressive decrease in $d E A A T 1$ transcription in addition to a shortened life-span and characteristic nuclear inclusions [85]. Delving deeper into the reasons behind 
the disruption of $d E A A T 1$ expression and thereby glial dysfunction, the authors found that this is partly the result of a disruption of the epidermal growth factor receptor signalling, a pathway implicated in independently upregulating glial glutamate transporter expression in mammalian cells. In addition to uncovering insights into the molecular and physiological effects of glutamate-mediated excitotoxicity, these studies are a proof of principle that the fruit fly can also serve as an effective model of excitotoxicity-induced neurodegeneration.

\section{Modelling RNA-Induced Neurodegeneration in the Fly}

In the past few years, RNA-based neurotoxic mechanisms have emerged as a novel cause of neurodegenerative conditions. Once transcribed from DNA, RNA undergoes complex processing that includes splicing and editing, and association with specific proteins that determine its subcellular localisation, stability and eventual translation into its cognate protein. All these aspects of RNA processing can be targeted in specific neuronal populations to cause a degenerative finale. Indeed this happens in several conditions including SMA and the non-coding trinucleotide repeat diseases, FXTAS and SCA8 (table 1).

\section{Non-Coding Trinucleotide Repeat Diseases}

These conditions are characterised by expansion of trinucleotide repeats within the $5^{\prime}$ or $3^{\prime}$ untranslated region or an intron of the respective gene. This can lead to loss of function of the disease gene, gain of function of the disease-associated mRNA, or both, resulting in neuronal dysfunction and degeneration. Fly models of some of these diseases have recently been established.

Fragile-X syndrome, a common form of inherited mental retardation, is caused by a substantial $(>200)$ CGG trinucleotide repeat expansion in the $5^{\prime}$ untranslated region of the FMR1 gene, termed 'full mutation', leading to transcriptional silencing and absence of the encoded FMR protein. The research on the physiological functions of the single Drosophila homologue of FMR1, $d F M R 1$, has left no stone unturned. dFMR1 is an RNAbinding protein that acts as a translational repressor. Experiments in Drosophila revealed that translational regulation may occur via the RNAi pathway [86-88]. Functionally relevant RNA targets of $\mathrm{dFMR} 1$ were found to include futsch, which encodes for a microtubule-associated protein with homology to mammalian MAP1B [89],
Racl, which encodes for a small GTPase [90], pickpocket1, which encodes for an ion channel subunit [91], chickadee, which is the Drosophila profilin homologue [92], and several others which remain to be characterised [93].

Homozygous loss of $d F M R 1$ is not lethal but mutant flies have abnormal circadian rhythms [94, 95], reduced courtship behaviour [94], abnormal locomotor behaviour $[89,91]$ and memory impairment $[96]$. At the anatomical level, $d F M R 1$ null mutants display enlarged NMJ synaptic terminals accompanied by altered neurotransmission [89], overgrown sensory neuron dendritic branches [90], disrupted morphology of the mushroom bodies [96,97], enhanced metabotropic glutamate receptor signalling [96] and neurite morphology defects [92].

The diverse phenotypes seen in $d F M R 1$ null flies are more or less similar to those observed in afflicted patients (who do not express the FMR1 message) including the marked absence of neurodegeneration. However, some fragile-X syndrome carriers have FMR1 alleles, termed premutations, whereby the number of CGG repeats is intermediate between that found in patients ( $>200$ repeats) and that observed in normal individuals ( $<55$ repeats). These patients exhibit a progressive neurodegeneration condition coined FXTAS. Clinical features of FXTAS include progressive intention tremor, gait ataxia, parkinsonism, cognitive deficits and autonomic dysfunction, whilst global brain atrophy and intranuclear inclusions present in both neurons and astrocytes throughout the CNS constitute the neuropathological hallmarks of this condition (for a review, see Hagerman and Hagerman [98]). Since FMR1 premutation alleles differ from both normal and full mutation alleles by producing more FMR1 transcripts with lengthy rCGG repeats [99, 100], the possibility of an RNA-mediated neurodegenerative mechanism was tested in transgenic animal models. Indeed, Jin et al. [101] reported that flies ectopically expressing a portion of the human FMR1 5' untranslated region containing either normal or premutation length rCGG repeats, exhibit a progressive neurodegenerative phenotype, the severity of which appeared to be dosage and repeat length dependent. Even though the CGG repeats were only transcribed but not translated, transgenic flies exhibited Hsp70- and ubiquitin-positive neuronal inclusion bodies, as observed in humans. This study suggests that in fragile-X premutation carriers, the long rCGG tract in FMR1 mRNA may attract and sequester rCGG interacting protein(s) from its normal functions, thereby affecting RNA metabolism and leading to progressive neuronal dysfunction and death. 
SCA8 is another neurodegenerative disease caused by a transcribed but untranslated CTG repeat expansion hypothesised to lead to a toxic RNA with impaired or altered cellular functions. A recent study in Drosophila has been central to understanding the molecular mechanisms underlying SCA8 pathology. Indeed, Mutsuddi et al. [102] found that when expressed in the fly retina, both wild-type and repeat-expanded SCA8 non-coding RNA induced late-onset, progressive neurodegeneration. Four neuronally expressed RNA binding proteins were found to modify this neurodegenerative phenotype, 2 of which exhibited different interaction strengths with wild-type versus repeat-expanded SCA8 backgrounds. Such results, combined with the demonstration that the interaction domain maps to the portion of the SCA8 RNA that undergoes repeat expansion in the human disease, seem to suggest that CUG expansions alter the association with specific RNA binding proteins possibly leading to titration of critical RNA binding proteins or other factors required for neuronal survival.

Of interest is a recent paper, which implicates that expansions within coding sequences may also result in neurotoxic RNA. Indeed, based on the observation that human Atx 2 and its Drosophila homologue dAtx 2 assemble with both polyribosomes and poly(A)-binding protein, a key regulator of mRNA translation, Satterfield and Pallanck [103] put forward the case that polyQ expansions within Atx2 cause neurodegeneration by interfering with the translation regulation of particular mRNAs.

\section{Spinal Muscular Atrophy}

SMA is considered a prime example of the deleterious repercussions a disruption in RNA processing can inflict on neuronal function. The prevalence of SMA among infants sets it apart from other neurodegenerative conditions, which usually do not become clinically evident until late in life. An autosomal recessive disease characterised by muscle weakness and atrophy due to degeneration of anterior horn spinal motor neurons, SMA is usually the result of mutations in the survival of motor neuron 1 (SMN1) gene resulting in loss of its protein product, SMN. Although humans carry a second SMN gene, termed $S M N 2$, an innate splicing defect renders this gene only partially functional and thereby unable to fully compensate for lack of protein encoding by SMN1. SMN is thought to be a major player in RNA metabolism including splicing through its role in the assembly of the spliceosome complex and mRNA localisation to the axon (reviewed in Monani [104] and Briese et al. [105]). Thus, in contrast to FXTAS and SCA8, SMA leads to RNA-mediated neuro- degeneration in a secondary or indirect way. Given the housekeeping role of SMN, the link between SMN's function and the very specific motor neuron disease phenotype observed in SMA has baffled researches on both sides of the Atlantic for nearly a decade. Using the humble fruit fly, our group has contributed some answers to this riddle.

Drosophila has a single highly homologous SMN orthologue, $d S M N$, and disruption of its oligomerisation using ectopic expression of human SMN gives rise to $\mathrm{pu}-$ pal lethality [106]. The presence of maternal wild-type $d S M N$ activity contributes to the survival of homozygous loss-of-function $d S M N$ mutants until the late larval stages where they develop abnormal motor behaviour [107]. The latter phenotype can be rescued only on driving expression of a rescue construct in both muscle and neuronal tissues. Explaining the observed motor deficits, $d S M N$ mutant larvae had electrophysiological defects and various abnormalities at the larval NMJ including disorganisation of synaptic boutons, increased number of enlarged boutons and, similar to SMA patients [108] and a recent SMA mouse model [109], reduced clustering of the neurotransmitter receptors [107]. More recently, we have shown for the first time that dSMN influences splicing of $e I F-4 E$, a rate-limiting translation initiation factor, and controls localisation and translation of specific transcripts in the well-characterised Drosophila egg chambers [unpubl. data]. These findings lead us to postulate that SMN may be an important player in the localisation and translational repression of specific neuronal transcripts especially those showing alternative splicing, and disruption of such processes can potentially lead to the motor neuron pathologies observed in SMA.

\section{From Forward Genetics to Neuropharmacology in Flies: A Promising Outlook}

The Nobel-prize-winning screens by Christiane Nüsslein-Volhard and Eric Wieschaus for embryonicpatterning mutants (part of these were published in a landmark paper describing segmentation in the fly [110]), ushered fly research into a new era. Indeed, this work unveiled the power of forward genetics in Drosophila to uncover mutants that influence a process of interest. In brief, forward genetic screens involve the introduction of random mutations at the genome level, screening of the resulting mutants for a specific phenotypic output and eventual mapping of the affected gene in the stabilised mutants. This journey makes forward genetics an unbi- 
Table 2. Examples of well-characterised neurodegenerative mutants isolated using forward genetics in Drosophila

\begin{tabular}{|c|c|c|c|}
\hline $\begin{array}{l}P \text { element insertion mutagenesis for } \\
\text { life-span-reducing mutants }\end{array}$ & $\begin{array}{l}\text { bubblegum mutant mapped to the } \\
\text { VLCFA acyl-coenzyme A synthetase- } \\
\text { like gene }\end{array}$ & $\begin{array}{l}\text { Adult neurodegeneration; elevated levels of } \\
\text { VLCFAs as seen in the human disease } \\
\text { adrenoleukodystrophy }\end{array}$ & 118 \\
\hline $\begin{array}{l}\text { EMS-induced mutagenesis for } \\
\text { life-span-reducing mutants; isolated } \\
\text { mutants were then examined for } \\
\text { histological neuropathology }\end{array}$ & eggroll mutant; gene not mapped & $\begin{array}{l}\text { Brain degeneration characterised by regionally } \\
\text { specific, membrane-bound vacuoles, similar to } \\
\text { those seen in spongiform degenerations } \\
\text { (e.g. Creutzfeldt-Jakob disease) } \\
\text { Brain degeneration characterised by dense, } \\
\text { multilamellated structures resembling those } \\
\text { found in lipid storage diseases (e.g. Tay-Sachs } \\
\text { disease) }\end{array}$ & 119 \\
\hline
\end{tabular}

EMS-induced mutagenesis followed by eye-specific expression of Flp recombinase to generate patches of homozygous mutant tissue; mutants isolated on whether the eyes develop substantial black degenerate tissue

$P$ element insertion mutagenesis for abnormal development of the peripheral nervous system burned mutant mapped to the $c p b$ locus encoding the $\beta$-subunit of the $\mathrm{F}$ actin capping protein; scorched mutant mapped to the cpa locus encoding the $\alpha$-subunit of the F actin capping protein

benchwarmer mutant mapped to the spinster gene which is predicted to encode a lysosomal sugar carrier
Mutant neuronal tissues characterised by accumulation of $\mathrm{F}$ actin consistent with the known function of the isolated genes in capping actin filaments and arresting their growth

$\begin{array}{ll}\text { Abnormal lysosomal carbohydrate storage, } & 121 \\ \text { synaptic defects, subsequent progressive } & 122 \\ \text { neuronal degeneration and enhanced } & \\ \text { tau-mediated toxicity suggesting aberrant } & \\ \text { lysosomal function and defects in endocytic } \\ \text { membrane trafficking }\end{array}$

EMS-induced mutagenesis for tempera- vacuous mutant; gene not mapped ture-sensitive paralytic mutants
Locomotor defects in both larvae and adults, neuronal hyperactivity and extensive age-dependent neurodegeneration throughout the CNS

Two mutants mapped to the same gene, $A T P a$, which encodes the $\alpha$-subunit (catalytic) of the $\mathrm{Na}^{+} / \mathrm{K}^{+}$-ATPase

Behavioural abnormalities, reduced life-span, age-dependent neurodegeneration suggesting severe neuronal hyperexcitability and extensive, that maintenance of neuronal viability is dependent on normal sodium pump activity

\begin{tabular}{ll}
\hline$P$ element insertion mutagenesis for & sniffer mutant mapped to the sniffer \\
mutants with histological adult brain & gene encoding a short-chain dehydro- \\
abnormalities & genase/reductase enzyme
\end{tabular}

EMS-induced mutagenesis for mutants exhibiting adult brain defects as determined by histology

EMS- and $P$-element-insertion-induced mutagenesis for mutants exhibiting adult structural brain defects as determined by histology

\begin{tabular}{ll}
\hline $\begin{array}{l}\text { Mutagenesis via } P \text { element enhancer } \\
\text { insertions for gene products exhibiting }\end{array}$ & $\begin{array}{l}\text { Effecter for neuronal death and degen- } \\
\text { eration 2 mutant mapped to the Sec61a } \\
\text { a gain-of-function by causing neural } \\
\text { gene which encodes for an endo- } \\
\text { cell loss }\end{array}$ \\
$\begin{array}{l}\text { plasmic-reticulum-associated protein } \\
\text { translocon }\end{array}$
\end{tabular}

swiss cheese mutant mapped to the swiss cheese gene encoding a protein sharing homology with vertebrate neuropathy target esterase

vacuolar peduncle mutant mapped to the RasGAP gene which encodes Ras GTPase-activating protein
Reduced life-span, a progressive sluggish walking phenotype and age-related neurodegeneration, possibly the result of oxidative stress

Progressive neurodegeneration, glial hyperwrapping, neuronal apoptosis and reduced 128 life-span

Age-related brain degeneration, possibly the result of deregulation of the EGFR/Ras signalling pathway

Neuronal cell death accompanied by the accumulation of ubiquitinated proteins

VLCFA = Very-long-chain fatty acid; EMS = ethyl methane sulphonate; EGFR = epidermal growth factor receptor. 
ased approach in contrast to reverse genetic approaches, which depend on existing genetic and often molecular knowledge. Applied to neurodegeneration research, forward genetic approaches in the fly are usually conducted in two ways. One arm involves the application of a random screen in a mutant background to uncover enhancers or suppressors of the disease phenotype [111] and the various uncovered modifiers in the fly neurodegenerative disease models were reviewed above. The other arm involves screening for mutations that reduce life-span, exhibit behavioural abnormalities or those that result in retinal degeneration. The latter strategy has been gaining momentum in recent years and so far has yielded several well-characterised genes encoding proteins that function to maintain neural function (table 2). Besides solidifying the mechanisms that function to maintain neural function with age, in the years to come, forward genetics has the potential to contribute valuable insights into neurodegenerative diseases whose aetiology is still unknown.

The successful modelling of neurodegenerative diseases in Drosophila and the striking rescue results achieved by administering potential drug compounds triggered a drive towards the use of flies in high-throughput therapeutic screens. In this respect, Drosophila offers several advantages over other models that make it a suitable choice for such screens. In contrast to the budding yeast (Saccharomyces cerevisiae), fruit flies are highly complex multicellular organisms and this renders them suitable for exploring any disease phenotype that disrupts a multicellular function. Unlike the nematode Caenorhabditis elegans, Drosophila also boasts an advanced nervous system with a segmented brain, a visual system, a lymphatic system similar to blood and a tracheal respiratory system, which are all features comparable to humans. While it is true that rodent models such as mice and rats are the preferred models for drug discovery and efficacy because their complex systems remarkably resemble our own, compared to flies, rodents are expensive to breed, maintain and use in large enough numbers in high-throughput drug discovery screens. However, Drosophila is not perfect and investigators using this model for the purpose of therapeutic discovery should bear in mind certain limitations including metabolic differences, problems with drug delivery, the necessity of validating positive 'hits' in mammalian systems, the lack of a blood-brain barrier that prevents assessment of delivery to the brain and difficulties in assessing side-effects. Despite these hurdles, various compounds identified in conventional screens were found to be also effective in several Drosophila models, thereby validating the use of flies to screen compounds as well as underscoring the potential of these specific compounds $[64,112-114]$. To conclude, if 'hits' can be validated in high-order organisms, flies do offer combined toxicity (if the animal survives after being fed the drug) and discovery in a quick, efficient and inexpensive package. Indeed, histone deacetylase inhibitors which were first discovered in fruit flies [59], confirmed in mice $[115,116]$ and presently tested in HD patients illustrate how employing fruit flies in the drug discovery pipeline holds promise for significant neuropharmacological recovery.

\section{Conclusion}

With nearly a century of genetic knowledge, it is no surprise that the humble fruit fly continues to stoke the fire of interest in gaining novel insights into human pathologies. This review should have given the reader an overview of how the fly has contributed to an understanding of neurodegenerative diseases, has led to the uncovering of new molecular pathways as potential therapeutic targets and importantly has provided insights that are directly translatable into higher-order systems. Hence we believe that Drosophila research must not be considered in a vacuum. Rather, it should complement work in other systems especially mammalian ones. Several successful stories utilizing a cross-species functional genomic approach have already been reported $[30,36]$ and we augur further studies in this style. The extensive genetic arsenal of the fruit fly combined with its acclaimed past contributions are a reflection that, in the years to come, this organism will always be one jump ahead of other systems in making novel discoveries in the field of neuroprotection and neurodegeneration.

\section{Acknowledgements}

The authors are immensely grateful to the fly community for making Drosophila a respectable model for human diseases and remain hugely indebted to all the funding agencies for their support throughout the years. 


\section{References}

1 Reiter LT, Potocki L, Chien S, Gribskov M, Bier E: A systematic analysis of human disease-associated gene sequences in Drosophila melanogaster. Genome Res 2001;11:11141125.

-2 Shubin N, Tabin C, Carroll S: Fossils, genes and the evolution of animal limbs. Nature 1997;3888:639-648.

-3 Rubin GM, Spradling AC: Genetic transformation of Drosophila with transposable element vectors. Science 1982;218:348-353.

-4 Brand AH, Perrimon N: Targeted gene expression as a means of altering cell fates and generating dominant phenotypes. Development 1993;118:401-415.

5 Ma Y, Creanga A, Lum L, Beachy PA: Prevalence of off-target effects in Drosophila RNA interference screens. Nature 2006;443:359363.

6 Golic KG: Site-specific recombination between homologous chromosomes in Drosophila. Science 1991;252:958-961.

7 Chou TB, Perrimon N: Use of a yeast sitespecific recombinase to produce female germline chimeras in Drosophila. Genetics 1992;131:643-653.

8 Chou TB, Noll E, Perrimon N: Autosomal $\mathrm{P}$ [ovoD1] dominant female-sterile insertions in Drosophila and their use in generating germ-line chimeras. Development 1993; 119:1359-1369.

$\checkmark 9$ Chou TB, Perrimon N: The autosomal FLPDFS technique for generating germline mosaics in Drosophila melanogaster. Genetics 1996;144:1673-1679.

10 Lee T, Luo L: Mosaic analysis with a repressible cell marker for studies of gene function in neuronal morphogenesis. Neuron 1999; 22:451-461.

11 Ghosh S, Feany MB: Comparison of pathways controlling toxicity in the eye and brain in Drosophila models of human neurodegenerative diseases. Hum Mol Genet 2004;13: 2011-2018.

-12 Nussbaum RL, Ellis CE: Alzheimer's disease and Parkinson's disease. N Engl J Med 2003; 348:1356-1364.

13 Rosen DR, Martin-Morris L, Luo LQ, White $\mathrm{K}$ : A Drosophila gene encoding a protein resembling the human $\beta$-amyloid protein precursor. Proc Natl Acad Sci USA 1989;86: 2478-2482.

14 Fossgreen A, Bruckner B, Czech C, Masters CL, Behreuther K, Paro R: Transgenic Drosophila expressing human amyloid precursor protein show $\gamma$-secretase activity and a blistered-wing phenotype. Proc Natl Acad Sci USA 1998;95:13703-13708.

15 Gunawardena S, Goldstein LSB: Disruption of axonal transport and neuronal viability by amyloid precursor protein mutations in Drosophila. Neuron 2001;32:389-401.
16 Torroja L, Chu H, Kotovsky I, White K: Neuronal overexpression of APPL, the Drosophila homologue of the amyloid precursor protein (APP), disrupts axonal transport. Curr Biol 1999;9:489-492.

17 Torroja L, Packard M, Gorczyca M, White K, Budnik V: The Drosophila $\beta$-amyloid precursor protein homolog promotes synapse differentiation at the neuromuscular junction. J Neurosci 1999;19:7793-7803.

18 Ye Y, Lukinova N, Fortini ME: Neurogenic phenotypes and altered Notch processing in Drosophila Presenilin mutants. Nature 1999 398:525-529.

19 Struhl G, Greenwald I: Presenilin is required for activity and nuclear access of Notch in Drosophila. Nature 1999;398:522-555.

20 Ye Y, Fortini ME: Apoptotic activities of wild-type and Alzheimer's disease-related mutant presenilins in Drosophila melanogaster. J Cell Biol 1999;146:1351-1364.

21 Seidner GA, Ye Y, Faraday MM, Alvord WG, Fortini ME: Modeling clinically heterogeneous presenilin mutations with transgenic Drosophila. Curr Biol 2006;16:1026-1033.

22 Iijima K, Liu HP, Chang AS, Hearn SA, Konsolaki M, Zhong Y: Dissecting the pathological effects of human A $\beta 40$ and $A \beta 42$ in Drosophila: a potential model for Alzheimer's disease. Proc Natl Acad Sci USA 2004;101 6623-6628.

23 Finelli A, Kelkar A, Song HJ, Yang H, Konsolaki M: A model for studying Alzheimer's A 342 -induced toxicity in Drosophila melanogaster. Mol Cell Neurosci 2004;26:365375.

24 Greeve I, Kretzchmar D, Tschape JA, Beyn A, Brellinger C, Schweizer M, Nitsch RM, Reifegerste R: Age-dependent neurodegeneration and Alzheimer-amyloid plaque formation in transgenic Drosophila. J Neurosci 2004;24:3899-3906.

25 Wittmann CW, Wszolek MF, Shulman JM, Salvaterra PM, Lewis J, Hutton M, Feany MB: Tauopathy in Drosophila: neurodegeneration without neurofibrillary tangles. Science 2001;293:711-714.

26 Jackson GR, Wiedau-Pazos M, Brown CA, Massachi S, Geschwind DH: Human wildtype tau interacts with wingless pathway components and produces neurofibrillary pathology in Drosophila. Neuron 2002;34: 509-519.

27 Mudher A, Shepherd D, Newman TA, Mildren P, Jukes JP, Squire A, Mears A, Berg S, MacKay D, Asuni AA, Bhat R, Lovestone S: GSK-3 $\beta$ inhibition reverses axonal transport defects and behavioural phenotypes in Drosophila. Mol Psychiatry 2004;9:522-530.

28 Chee FC, Mudher A, Cuttle MF, Newman TA, MacKay D, Lovestone S, Shepherd D: Over-expression of tau results in defective synaptic transmission in Drosophila neuromuscular junctions. Neurobiol Dis 2005;20: 918-928.
29 Shulman JM, Feany MB: Genetic modifiers of tauopathy in Drosophila. Genetics 2003; 165:1233-1242.

30 Karsten SL, Sang TK, Gehman LT, Chatterjee S, Liu J, Lawless GM, Sengupta S, Berry RW, Pomakian J, Oh HS, Schulz C, Hui KS, Wiedau-Pazos M, Vinters HV, Binder LI, Geschwind DH, Jackson GR: A genomic screen for modifiers of tauopathy identifies puromycin-sensitive aminopeptidase as an inhibitor of tau-induced neurodegeneration. Neuron 2006;51:549-560.

31 Coulom H, Birman S: Chronic exposure to rotenone models sporadic Parkinson's disease in Drosophila melanogaster. J Neurosci 2004;24:10993-10998.

-32 Feany MB, Bender WW: A Drosophila model of Parkinson's disease. Nature 2000;404: 394-398.

33 Chen L, Feany MB: $\alpha$-Synuclein phosphorylation controls neurotoxicity and inclusion formation in a Drosophila model of Parkinson disease. Nat Neurosci 2005;8:657-663.

>34 Auluck PK, Chan HY, Trojanowski JQ, Lee VM, Bonini NM: Chaperone suppression of alpha-synuclein toxicity in a Drosophila model for Parkinson's disease. Science 2002. 295:865-868.

35 Auluck PK, Bonini NM: Pharmacological prevention of Parkinson disease in Drosophila. Nat Med 2002;8:1185-1186.

36 Cooper AA, Gitler AD, Cashikar A, Haynes CM, Hill KJ, Bhullar B, Liu K, Xu K, Strathearn KE, Liu F, Cao S, Caldwell KA, Caldwell GA, Marsischky G, Kolodner RD, LaBaer J, Rochet JC, Bonini NM, Lindquist S: $\alpha$-Synuclein blocks ER-Golgi traffic and Rab1 rescues neuron loss in Parkinson's models. Science 2006;313:324-328.

37 Scherzer CR, Jensen RV, Gullans SR, Feany $\mathrm{MB}$ : Gene expression changes presage neurodegeneration in a Drosophila model of Parkinson's disease. Hum Mol Genet 2003; 12:2457-2466

38 Greene JC, Whitworth AJ, Kuo I, Andrews LA, Feany MB, Pallanck LJ: Mitochondrial pathology and apoptotic muscle degeneration in Drosophila parkin mutants. Proc Natl Acad Sci USA 2003;100:4078-4083.

39 Pesah Y, Pham T, Burgess H, Middlebrooks B, Verstreken P, Zhou Y, Harding M, Bellen H, Mardon G: Drosophila parkin mutants have decreased mass and cell size and increased sensitivity to oxygen radical stress. Development 2004;131:2183-2194.

40 Whitworth AJ, Theodore DA, Greene JC, Benes H, Wes PD, Pallanck LJ: Increased glutathione S-transferase activity rescues dopaminergic neuron loss in a Drosophila model of Parkinson's disease. Proc Natl Acad Sci USA 2005;102:8024-8029. 
-41 Yang Y, Nishimura I, Imai Y, Takahashi R, Lu B: Parkin suppresses dopaminergic neuronselective neurotoxicity induced by Pael-R in Drosophila. Neuron 2003;37:911-924.

-42 Greene JC, Whitworth AJ, Andrews LA, Parker TJ, Pallanck LJ: Genetic and genomic studies of Drosophila parkin mutants implicate oxidative stress and innate immune responses in pathogenesis. Hum Mol Genet 2005;14:799-811.

-43 Meulener M, Whitworth AJ, ArmstrongGold CE, Rizzu P, Heutink P, Wes PD, Palladino MJ, Bonini NM: Drosophila DJ-1 mutants are selectively sensitive to environmental toxins associated with Parkinson's disease. Curr Biol 2005;15:1572-1577.

44 Menzies FM, Yenisetti SC, Min KT: Roles of Drosophila DJ-1 in survival of dopaminergic neurons and oxidative stress. Curr Biol 2005; 15:1578-1582.

-45 Park J, Kim SY, Cha GH, Lee SB, Kim S, Chung J: Drosophila DJ-1 mutants show oxidative stress-sensitive locomotive dysfunction. Gene 2005;361:133-139.

-46 Yang Y, Gehrke S, Haque ME, Imai Y, Kosek J, Yang L, Beal MF, Nishimura I, Wakamatsu K, Ito S, Takahashi R, Lu B: Inactivation of Drosophila DJ-1 leads to impairments of oxidative stress response and phosphatidylinositol 3-kinase/Akt signalling. Proc Natl Acad Sci USA 2005;102:13670-13675.

47 Valente EM, Abou-Sleiman PM, Caputo V, Muqit MM, Harvey K, Gispert Z, Zeeshan A, Del Turco D, Bentivoglio AR, Healy DG, Albanese A, Nussbaum R, Gonzalez-Maldonado R, Deller T, Salvi S, Cortelli P, Gilks WP, Latchman DS, Harvey RJ, Dallapiccola B, Auburger G, Wood NW: Hereditary early-onset Parkinson's disease caused by mutations in PINK1. Science 2004;304:1158-1160.

-48 Yang Y, Gehrke S, Imai Y, Huang Z, Ouyang Y, Wang JW, Yang L, Beal MF, Vogel H: Mitochondrial pathology and muscle and dopaminergic neuron degeneration caused by inactivation of Drosophila Pink1 is rescued by Parkin. Proc Natl Acad Sci USA 2006;103: 10793-10798.

49 Park J, Lee SB, Lee S, Kim Y, Song S, Kim S, Bae E, Kim J, Shong M, Kim JM, Chung J: Mitrochondrial dysfunction in Drosophila PINK1 mutants is complemented by parkin. Nature 2006;441:1157-1161.

-50 Clark IE, Dodson MW, Jiang C, Cao JH, Huh JR, Seol JH, Yoo SJ, Hay BA, Guo M: Drosophila pink1 is required for mitochondrial function and interacts genetically with parkin. Nature 2006;441:1162-1166.

-51 Wang D, Qian L, Xiong H, Liu J, Neckameyer WS, Oldham S, Xia K, Wang J, Bodmer R, Zhang Z: Antioxidants protect PINK1-dependent dopaminergic neurons in Drosophila. Proc Natl Acad Sci USA 2006;103:1352013525.
52 Marsh JL, Walker H, Theisen H, Zhu YZ, Fielder T, Purcell J, Thompson LM: Expanded polyglutamine peptides alone are intrinsically cytotoxic and cause neurodegeneration in Drosophila. Hum Mol Genet 2000;9: 13-25.

53 Kazemi-Esfarjani P, Benzer S: Genetic suppression of polyglutamine toxicity in Drosophila. Science 2000;287:1837-1840.

54 Kazemi-Esfarjani P, Benzer S: Suppression of polyglutamine toxicity by a Drosophila homolog of myeloid leukemia factor 1 . Hum Mol Genet 2002;11:2657-2672.

55 Iijima-Ando K, Wu P, Drier EA, Iijima K, Yin JCP: cAMP-response element-binding protein and heat-shock protein 70 additively suppress polyglutamine-mediated toxicity in Drosophila. Proc Natl Acad Sci USA 2005; 102:10261-10266.

56 WarrickJM, Morabito LM, Bilen J, GordeskyGold B, Faust LZ, Paulson HL, Bonini NM: Ataxin-3 suppresses polyglutamine neurodegeneration in Drosophila by a ubiquitinassociated mechanism. Mol Cell 2005;18: 37-48.

57 Al-Ramahi I, Lam YC, Chen HK, de Gouyon B, Zhang M, Perez AM, Branco J, de Haro M, Patterson C, Zoghbi HY, Botas J: CHIP protects from the neurotoxicity of expanded and wild-type ataxin-1 and promotes their ubiquitination and degradation. J Biol Chem 2006;281:26714-26724.

58 Gunawardena S, Her LS, Brusch RG, Laymon RA, Niesman IR, Gordesky-Gold B, Sintasath L, Bonini NM, Goldstein LSB: Disruption of axonal transport by loss of huntingtin or expression of pathogenic polyQ proteins in Drosophila. Neuron 2003; 40:25.

59 Steffan JS, Bodal L, Pallos J, Poelman M, McCampbell A, Apostol BL, Kazantsev A, Schmidt E, Zhu YZ, Greenwald M, Kurokawa R, Housman DE, Jackson GR, Marsh JL, Thompson LM: Histone deacetylase inhibitors arrest polyglutamine-dependent neurodegeneration in Drosophila. Nature 2001; 413:739-743.

60 Jackson GR, Salecker I, Dong X, Yao X, Arnheim N, Faber PW, MacDonald ME, Zipursky SL: Polyglutamine-expanded human huntingtin transgenes induce degeneration of Drosophila photoreceptor neurons. Neuron 1998;21:633-642.

61 Lee WC, Yoshihara M, Littleton JT: Cytoplasmic aggregates trap polyglutamine-containing proteins and block axonal transport in a Drosophila model of Huntington's disease. Proc Natl Acad Sci USA 2004;101: 3224-3229.

62 Kazantsev A, Walker HA, Slepko N, Bear JE, Preisinger E, Steffan JS, Zhu YZ, Gertler FB, Housman DE, Marsh JL, Thompson LM: A bivalent Huntingtin binding peptide suppresses polyglutamine aggregation and pathogenesis in Drosophila. Nat Genet 2002; 30:367-376.
63 Steffan JS, Agrawal N, Pallos J, Rockabrand E, Trotman LC, Slepko N, Illes K, Lukacsovich T, Zhu YZ, Cattaneo E, Pandolfi PP, Thompson LM, Marsh JL: SUMO modification of Huntingtin and Huntington's disease pathology. Science 2004;304:100-104.

64 Ravikumar B, Vacher C, Berger Z, Davies JE, Luo S, Oroz LG, Scaravilli F, Easton DF Duden R, O'Kane CJ, Rubinsztein DC: Inhibition of mTOR induces autophagy and reduces toxicity of polyglutamine expansions in fly and mouse models of Huntington disease. Nat Genet 2004;36:585-595.

65 Berger Z, Ravikumar B, Menzies FM, Oroz LG, Underwood BR, Pangalos MN, Schmitt I, Wullner U, Evert BO, O’Kane CJ, Rubinsztein DC: Rapamycin alleviates toxicity of different aggregate-prone proteins. Hum Mol Genet 2006;15:433-442.

66 Warrick JM, Paulson HL, Gray-Board GL, Bui QT, Fischbeck KH, Pittman RN, Bonini NM: Expanded polyglutamine protein forms nuclear inclusions and causes neural degeneration in Drosophila. Cell 1998;93:939949.

67 Warrick JM, Chan HY, Gray-Board GL, Chai Y, Paulson HL, Bonini NM: Suppression of polyglutamine-mediated neurodegeneration in Drosophila by the molecular chaperone HSP70. Nat Genet 1999;23:425-428.

-68 Satterfield TF, Jackson SM, Pallanck LJ: A Drosophila homolog of the polyglutamine disease gene SCA2 is a dosage-sensitive regulator of actin filament formation. Genetics 2002;162:1687-1702.

69 Fernandez-Funez P, Nino-Rosales ML, de Gouyon B, She WC, Luchak JM, Martinez P, Turiegano E, Benito J, Capovilla M, Skinner PJ, McCall A, Canal I, Orr HT, Zoghbi HY, Botas J: Identification of genes that modify ataxin-1-induced neurodegeneration. $\mathrm{Na}$ ture 2000;408:101-106.

70 Chen HK, Fernandez-Funez P, Acevedo SF, Lam YC, Kaytor MD, Fernandez MH, Aitken A, Skoulakis EMC, Orr HT, Botas J, Zoghbi HY: Interaction of Akt-phosphorylated ataxin-1 with 14-3-3 mediates neurodegeneration in spinocerebellar ataxia type 1 . Cell 2003;113:457-468.

71 Tsai CC, Kao HY, Mitzutani A, Banayo E, Rajan H, McKeown M, Evans RM: Ataxin 1, a SCA1 neurodegenerative disorder protein is functionally linked to the silencing mediator of retinoid and thyroid hormone receptors. Proc Natl Acad Sci USA 2004;101:40474052.

72 Tsuda H, Jafar-Nejad H, Patel AJ, Sun Y, Chen HK, Rose MF, Venken KJT, Botas J, Orr HT, Bellen HJ, Zoghbi HY: The AXH domain of ataxin-1 mediates neurodegeneration through its interaction with Gfi-1/ Senseless proteins. Cell 2005;122:633-644. 
-73 Lim J, Hao T, Shaw C, Patel AJ, Szabo G, Rual JF, Fisk CJ, Li N, Smolyar A, Hill DE, Barabasi AL, Vidal M, Zoghbi HY: A protein-protein interaction network for human inherited ataxias and disorders of Purkinje cell degeneration. Cell 2006;125:801-814.

-74 Takeyama K, Ito S, Yamamoto A, Tanimoto H, Furutani T, Kanuka H, Miura M, Tabata T, Kato S: Androgen-dependent neurodegeneration by polyglutamine-expanded human androgen receptor in Drosophila. Neuron 2002;35:855-864.

75 Rowland LP, Shneider NA: Amyotrophic lateral sclerosis. N Engl J Med 2001;344:16881700.

-76 Mockett RJ, Radyuk SN, Benes JJ, Orr WC, Sohal RS: Phenotypic effects of familial amyotrophic lateral sclerosis mutant Sod alleles in transgenic Drosophila. Proc Natl Acad Sci USA 2003;100:301-306.

-77 Phillips JP, Tainer JA, Getzoff ED, Boulianne GL, Kirby K, Hilliker AJ: Subunit-destabilizing mutations in Drosophila copper/zinc superoxide dismutase: neuropathology and a model of dimer dysequilibrium. Proc Natl Acad Sci USA 1995;92:8574-8578.

-78 Parkes TL, Elia AJ, Dickinson D, Hilliker AJ, Phillips JP, Boulianne GL: Extension of Drosophila lifespan by overexpression of human SOD1 in motorneurons. Nat Genet 1998;19: 171-174.

79 Fink JK, Rainier S: Hereditary spastic paraplegia: spastin phenotype and function. Arch Neurol 2004;61:849-855.

-80 Hazan J, Fonknechten N, Mavel D, Paternotte C, Samson D, Artiguenava F, Davoine CS, Cruaud C, Durr A, Wincker P, Brottier P, Cattolico L, Barbe V, Burgunder JM, Prud'homme JF, Brice A, Fontaine B, Heilig $\mathrm{R}$, Weissenbach J: Spastin, a new AAA protein, is altered in the most frequent form of autosomal dominant spastic paraplegia. Nat Genet 1999;23:296-303.

81 Sherwood NT, Sun Q, Xue M, Zhang B, Zinn $\mathrm{K}$ : Drosophila Spastin regulates synaptic microtubule networks and is required for normal motor function. PLoS Biol 2004;2:e429.

-82 Orso G, Martinuzzi A, Rossetto MG, Sartori E, Feany MB, Daga A: Disease-related phenotypes in a Drosophila model of hereditary spastic paraplegia are ameliorated by treatment with vinblastine. J Clin Invest 2005; 115:2968-2971.

83 Salinska E, Danysz W, Lazarewicz JW: The role of excitotoxicity in neurodegeneration. Folia Neuropathol 2005;43:322-339.

-84 Rival T, Soustelle L, Strambi C, Besson MT, Iche $\mathrm{M}$, Birman S: Decreasing glutamate buffering capacity triggers oxidative stress and neuropil degeneration in the Drosophila brain. Curr Biol 2004;14:599-605.

-85 Lievens JC, Rival T, Iche M, Chneiweiss H, Birman S: Expanded polyglutamine peptides disrupt EGF receptor signaling and glutamate transporter expression in Drosophila. Hum Mol Genet 2005;14:713-724.
86 Jin P, Zarnescu DC, Ceman S, Nakamoto M, Mowrey J, Jongens TA, Nelson DL, Moses K, Warren ST: Biochemical and genetic interaction between the fragile $\mathrm{X}$ mental retardation protein and the microRNA pathway. Nat Neurosci 2004;7:113-117.

87 Ishizuka A, Siomi MC, Siomi H: A Drosophila fragile $\mathrm{X}$ protein interacts with components of RNAi and ribosomal proteins. Genes Dev 2002;16:2497-2508.

88 Caudy AA, Myers M, Hannon GJ, Hammond SM: Fragile X-related protein and VIG associate with the RNA interference machinery. Genes Dev 2002;16:2491-2496.

89 Zhang YQ, Bailey AM, Matthies HJG, Renden RB, Smith MA, Speese SD, Rubin GM, Broadie K: Drosophila Fragile X-related gene regulates the MAP1B homolog Futsch to control synaptic structure and function. Cell 2001;107:591-603.

-90 Lee A, Li W, Xu K, Bogert BA, Su K, Gao FB: Control of dendritic development by the Drosophila fragile X-related gene involves the small GTPase Rac1. Development 2003; 130:5543-5552.

-91 Xu K, Bogert BA, Li W, Su K, Lee A, Gao FB: The fragile X-related gene affects crawling behaviour of Drosophila larvae by regulating the mRNA level of the DEG/ENaC protein pickpocket1. Curr Biol 2004;14:1025-1034.

-92 Reeve SP, Bassetto L, Genova GK, Kleyner Y, Leyssen M, Jackson FR, Hassan BA: The Drosophila fragile $\mathrm{X}$ mental retardation protein controls actin dynamics by directly regulating profilin in the brain. Curr Biol 2005; 15:1156-1163.

93 Zarnescu DC, Jin P, Betschinger J, Nakamoto M, Wang Y, Dockendorff TC, Feng Y, Jongens TA, Sisson JC, Knoblich JA, Warren ST, Moses K: Fragile X protein functions with $\mathrm{Lgl}$ and the PAR complex in flies and mice. Dev Cell 2005;8:43-52.

$\checkmark 94$ Dockendorff TC, Su HS, McBride SM, Yang Z, Choi CH, Siwicki KK, Sehgal A, Jongens TA: Drosophila lacking dfmrl activity show defects in circadian output and fail to maintain courtship interest. Neuron 2002;34: 973-984.

-95 Morales J, Hiesinger R, Schroeder AJ, Kume K, Verstreken P, Jackson FR, Nelson DL, Hassan BA: Drosophila fragile X protein, DFXR, regulates neuronal morphology and function in the brain. Neuron 2002;34:961972.

96 McBride SM, Choi CH, Wang Y, Liebelt D, Braunstein E, Ferreiro D, Sehgal A, Siwicki KK, Dockendorff TC, Nguyen HT, McDonald TV, Jongens TA: Pharmacological rescue of synaptic plasticity, courtship behavior, and mushroom body defects in a Drosophila model of fragile X syndrome. Neuron 2005; 45:753-764.
97 Michel CI, Kraft R, Restifo LL: Defective neuronal development in the mushroom bodies of Drosophila fragile X mental retardation 1 mutants. J Neurosci 2004;24: 5789-5809.

98 Hagerman PJ, Hagerman RJ: The fragile-X premutation: a maturing perspective. Am J Hum Genet 2004;74:805-816.

$\checkmark 99$ Tassone F, Hagerman RJ, Taylor AK, Gane LW, Godfrey TE, Hagerman PJ: Elevated levels of FMR1 mRNA in carrier males: a new mechanism of involvement in the fragile-X syndrome. Am J Hum Genet 2000;66: 6-15.

100 Kenneson A, Zhang F, Hagedorn CH, Warren ST: Reduced FMRP and increased FMR1 transcription is proportionally associated with CGG repeat number in intermediate-length and premutation carriers. Hum Mol Genet 2001;1:1449-1454.

101 Jin P, Zarnescu DC, Zhang F, Pearson CE, Lucchesi JC, Moses K, Warren ST: RNAmediated neurodegeneration caused by the fragile X premutation rCGG repeats in Drosophila. Neuron 2003;39:739-747.

102 Mutsuddi M, Marshall CM, Benzow KA, Koob MD, Rebay I: The spinocerebellar ataxia 8 noncoding RNA causes neurodegeneration and associates with Staufen in Drosophila. Curr Biol 2004;14:302-308.

103 Satterfield TF, Pallanck LJ: Ataxin-2 and its Drosophila homolog, ATX2, physically assemble with polyribosomes. Hum $\mathrm{Mol}$ Genet 2006;15:2523-2532.

104 Monani UR: Spinal muscular atrophy: a deficiency in a ubiquitous protein, a motor neuron-specific disease. Neuron 2005;48: 885-896.

105 Briese M, Esmaeili B, Sattelle DB: Is spinal muscular atrophy the result of defects in motor neuron processes? Bioessays 2005; 27:946-957.

106 Miguel-Aliaga I, Chan YB, Davies KE, van den Heuvel M: Disruption of SMN function by ectopic expression of the human SMN gene in Drosophila. FEBS Lett 2000;486: 99-102.

107 Chan YB, Miguel-Aliaga I, Franks C, Thomas N, Trulzsch B, Sattelle DB, Davies KE, van den Heuvel M: Neuromuscular defects in a Drosophila survival motor neuron gene mutant. Hum Mol Genet 2003;12: 1367-1376.

108 Arnold AS, Gueye M, Guettier-Sigrist S, Courdier-Fruh I, Coupin G, Poindron P, Gies JP: Reduced expression of nicotinic AChRs in myotubes from spinal muscular atrophy I patients. Lab Invest 2004;84: 1271-1278.

109 Le TT, Pham LT, Butchbach MER, Zhang HL, Monani UR, Coovert DD, Gavrilina TO, Xing L, Bassell GJ, Burghes AHM: SMNDelta7, the major product of the centromeric survival motor neuron (SMN2) gene, extends survival in mice with spinal muscular atrophy and associates with full-length SMN. Hum Mol Genet 2005;14:845-857. 
-110 Nüsslein-Volhard C, Wieschaus E: Mutations affecting segment number and polarity in Drosophila. Nature 1980;287:795801.

-111 Simon MA, Bowtell DD, Dodson GS, Laverty TR, Rubin GM: Ras1 and a putative guanine nucleotide exchange factor perform crucial steps in signaling by the sevenless protein tyrosine kinase. Cell 1991;67: 701-716.

-112 Desai UA, Pallos J, Ma AAK, Stockwell BR, Thompson LM, Marsh JL, Diamond MI: Biologically active molecules that reduce polyglutamine aggregation and toxicity. Hum Mol Genet 2006;15:2114-2124.

-113 Pollit SK, Pallos J, Shao J, Desai UA, Ma AA, Thompson LM, Marsh JL, Diamond MI: A rapid cellular FRET assay of polyglutamine aggregation identifies a novel inhibitor. Neuron 2003;40:685-694.

114 Apostol BL, Kazantsev A, Raffioni S, Illes K, Pallos J, Bodai L, Slepko N, Bear JE, Gertler FB, Hersch S, Housman DE, Marsh JL, Thompson LM: A cell-based assay for aggregation inhibitors as therapeutics of polyglutamine-repeat disease and validation in Drosophila. Proc Natl Acad Sci USA 2003;100:5950-5955.

115 Hockly E, Richon VM, Woodman B, Smith DL, Zhou X, Rosa E, Sathasivam K, GhaziNoori S, Mahal A, Lowden PAS, Steffan JS, Marsh JL, Thompson LM, Lewis CM, Marks PA, Bates GP: Suberoylanilide hydroxamic acid, a histone deacetylase inhibitor, ameliorates motor deficits in a mouse model of Huntington's disease. Proc Natl Acad Sci USA 2003;100:2041-2046.
116 Ferrante RJ, Kubilus JK, Lee J, Ryu H, Beesen A, Zucker B, Smith K, Kowall NW, Ratan RR, Luthi-Carter R, Hersch SM: Histone deacetylase inhibition by sodium butyrate chemotherapy ameliorates the neurodegenerative phenotype in Huntington's disease mice. J Neurosci 2003;23:94189427.

117 Trotta N, Orso G, Rossetto MG, Daga A, Broadie K: The hereditary spastic paraplegia gene, spastin, regulates microtubule stability to modulate synaptic structure and function. Curr Biol 2004;14:11351147.

118 Min KT, Benzer S: Preventing neurodegeneration in the Drosophila mutant bubblegum. Science 1999;284:1985-1988.

119 Min KT, Benzer S: Spongecake and eggroll: two hereditary diseases in Drosophila resemble patterns of human brain degeneration. Curr Biol 1997;7:885-888.

120 Delalle I, Pfleger CM, Buff E, Lueras P, Hariharan IK: Mutations in the Drosophila orthologs of the F-actin capping protein $\alpha$ and $\beta$-subunits cause actin accumulation and subsequent retinal degeneration. Genetics 2005;171:1757-1765.

121 Kania A, Salzberg A, Bhat M, D’Evelyn D, He Y, Kiss I, Bellen HJ: P-element mutations affecting embryonic peripheral nervous system development in Drosophila melanogaster. Genetics 1995;139:16631678.

122 Dermaut B, Norga KK, Kania A, Verstreken P, Pan H, Zhou Y, Callaerts P, Bellen H: Abberrant lysosomal carbohydrate storage accompanies endocytic defects and neurodegeneration in Drosophila benchwarmer. J Cell Biol 2005;170:127-139.

123 Palladino MJ, Hadley TJ, Ganetzky B: Temperature-sensitive paralytic mutants are enriched for those causing neurodegeneration in Drosophila. Genetics 2002;161: 1197-1208.
124 Palladino MJ, Bower JE, Kreber R, Ganetzky B: Neural dysfunction and neurodegeneration in Drosophila $\mathrm{Na}^{+} / \mathrm{K}^{+}$ATPase $\alpha$ subunit mutants. J Neurosci 2003;23: 1276-1286.

125 Melzig J, Rein KH, Schafer U, Pfister H, Jackle H, Heisenberg M, Raabe T: A protein related to p21-activated kinase (PAK) that is involved in neurogenesis in the Drosophila adult central nervous system. Curr Biol 1998;8:1223-1226.

126 Ryder E, Russell S: Transposable elements as tools for genomics and genetics in Drosophila. Brief Funct Genomic Proteomic 2003;2:57-71.

127 Kretzchmar D, Hasan G, Sharma S, Heisenberg M, Benzer S: The Swiss cheese mutant causes glial hyperwrapping and brain degeneration in Drosophila. J Neurosci 1997; 17:7425-7432.

128 Muhlig-Versen M, Bettencout da Cruz A, Tschape JA, Moser M, Buttner R, Athenstaedt K, Glynn P, Kretzchmar D: Loss of Swiss cheese/neuropathy target esterase activity causes disruption of phosphatidylcholine homeostasis and neuronal and glial death in adult Drosophila. J Neurosci 2005; 25:2865-2873.

129 Botella JA, Kretzchmar D, Kiermayer C, Feldmann P, Hughes DA, Schneuwly S: Deregulation of the Egfr/Ras signalling pathway induces age-related brain degeneration in the Drosophila mutant vap. Mol Biol Cell 2003;14:241-250.

130 Kanuka H, Hiratou T, Igaki T, Kanda H, Kuranaga E, Sawamoto K, Aigaki T, Okano H, Miura M: Gain-of-function screen identifies a role of the $S e c 61 \alpha$ translocon in Drosophila postmitotic neurotoxicity. Biochim Biophys Acta 2005;1726:225-237. 